\title{
Patients Acceptance and Comprehension to Written and Verbal Consent (PAC-VC)
}

\section{Rabia Kashur}

University of Alberta

Justin Ezekowitz

University of Alberta

Shane Kimber

University of Alberta

Robert Welsh ( $\square$ robert.welsh@ahs.ca )

University of Alberta https://orcid.org/0000-0003-2613-9142

Research article

Keywords: Informed consent, Acute Myocardial Infarction, Verbal Assent, Written Consent, Clinical Trials

Posted Date: March 1st, 2021

DOl: https://doi.org/10.21203/rs.3.rs-264330/v1

License: (c) (1) This work is licensed under a Creative Commons Attribution 4.0 International License.

Read Full License 


\section{Abstract}

\section{Background:}

Acute myocardial infarction (AMI) research is challenging as it requires enrollment of acutely ill patients. Patients are generally in a suboptimal state for providing informed consent. Patients' understanding to verbal assents have not been previously examined in AMI research. Patients $\underline{A}$ cceptance and Comprehension to Written and Verbal $\underline{C}$ onsent (PAC-VC) compared patients' understanding and attitudes to verbal and written consents in AMI RCTs.

\section{Methods:}

PAC-VC recruited patients from 3 AMI trials using both verbal $\mathrm{N}=12$ and written $\mathrm{N}=6$ consents. We compared patients' understanding using two survey questionnaires. The first questionnaire used openended questions with multiple choice answers. The second questionnaire used a 5-point Likert scale to measure patients understanding and attitudes to the consent process. Overall answers average scores were categorized into three groups: Adequate understanding (71-100) \%, Partial understanding (41-70)\% and Inadequate understanding $(0-40) \%$.

\section{Results:}

Responses showed patients with verbal assent had adequate understanding to most components of informed consent, close to those of written consent. Most patients did not read written information entirely and believed that it is not important to make a final decision. Patients favoured to have written information be part of the consent but not necessarily presented during the initial consent process. Patients felt less pressured in the verbal assent arm than those of written consent.

\section{Conclusion:}

Patients had adequate understanding to most components of verbal assent and comparable to those of written consent. Utilizing verbal assents in the acute care setting should be further assessed in larger trials.

\section{Background}

The concept of informed consent has a legacy of going back to the 1767 when an English court prevented experimentation on patients without obtaining consent.(1) Since the inception of this concept, informed consent has gone through many adjustments to reach the current definition. The International Council of Harmonization (ICH) defines informed consent as a process by which subjects voluntarily confirm their willingness to participate in a study after having been informed of all aspects relevant to the subjects' decision. Informed consent relies on three principles: disclosure of adequate information about the study, subjects understand the information provided, and voluntariness to give consent.(2) 
Randomized clinical trials (RCTs) are essential to develop new treatment strategies as well as to refine existing ones for acute and chronic medical conditions. Acute myocardial infarction (AMI) research presents a special challenge. It often requires enrollment of critically ill patients who are distressed and require urgent therapy to prevent morbidity and potential mortality. Evidence suggests that patients in this category are generally in a suboptimal state to understand or remember facts related to their condition and planned interventions.(3-5) It also suggests that many patients who consent to AMI trials remember the main information, however their degree of understanding and perceived comprehension was subjective and often questionable.(6) Patients in this category of AMI research found it irrational to be expected to read written material in an acute phase of a heart attack.(6) Instead, patients turn to oral information and explanations as a substitute. $(4,7,8)$

Despite the current evidence, verbal assent has not been formally examined nor compared to the conventional written consents. Additionally, previous studies assessed patient comprehension by simply seeking their subjective opinions about their level of understanding or using the degree of information

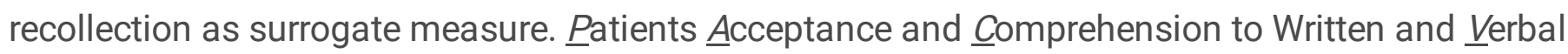
Consent (PAC-VC) is designed to compare patient' perspectives and understanding to verbal and written consents in AMI trials.

\section{Methods}

\section{Study Design}

This was a questionnaire-based study conducted at the Mazankowski Alberta Heart Institute from April 2014 to June 2015. During this time, PAC-VC recruited patients from 3 ongoing AMI RCTs: Remote ischemic conditioning in ST-Elevation myocardial infarction research (REMCON-STEMI), Complete vs Culprit-only Revascularization to Treat Multi-vessel Disease After Early PCI for STEMI (COMPLETE) and routine aspiration ThrOmbecTomy with $\mathrm{PCl}$ versus PCI ALone in patients with STEMI undergoing primary $\mathrm{PCI}$ (TOTAL). REMCON-STEMI trial consented patients using verbal script delivered by Emergency Medical services (EMS) personnel during enrollment to obtain a verbal assent. This was performed by only reading a script to study participants with no supplementary material to read at the initial enrollment process. Once the patients have received their treatment and stabilized, a second formal written consent is obtained by a research nurse within 72 hours when the written material is provided. TOTAL and COMPLETE trials used the traditional written consents process. The main difference between the two arms was the availability of the written material to patients in the traditional written consent arm, while on the verbal arm an initial verbal script and explanation was provided, followed by the written information for review at later time once their treatment is completed. Approval from our research ethics board was obtained prior to initiating recruitment. Written information readability grade level ranged from 10 to 13 at the Flesch-Kincaid Grade Level test.

\section{Recruitment}


Once patients were randomized to one of the determined 3 AMI trials, notification was sent to the research team to screen potential patients for eligibility. Of 21 patients initially approached, 18 consented to participate. PAC-VC enrolled patients into two parallel arms: verbal and written. The verbal arm recruited patients from the REMCON-STEMI trial in the acute phase who provided verbal assent and had not yet provided written consent. The written arm enrolled patients from the COMPLETE and TOTAL trials. Patients from all studies were approached within 72 hours from their randomization to the original AMI trials once deemed medically stable. Patients were approached to participate in PAC-VC and the assessment of their comprehension was done by administering a survey questionnaire as shown in Figure 1.

\section{Study Population}

All patients who consented to REM-CON, COMPLETE and/or TOTAL trials were screened for eligibility. Patients were excluded if they were unconscious, hemodynamically unstable, has dementia or mental illness or patients who gave consent through a proxy or a substitute decision maker.

\section{Assessment Tools and Data Collection}

PAC-VC used two sets of survey questionnaires to assess qualitative and quantitative responses of the subjects. The first set used open-ended questions with multiple choice answers. The questions tested patients' understanding of the core components of informed consent. This part was designed to objectively test patients' understanding. The second part used a Likert scale to measure perceived patients' understanding about the trials in addition to the assessment of patients' attitudes and perspectives towards the consent process. Both parts of the questionnaire were reviewed by the research team in addition to an external expert to assess relevance of the content.

\section{Scoring}

Patients' responses for the objective assessment (Part 1) were assigned scores according to the answers. Correct answers were granted a complete score of 100\%. Incorrect answers were scored 0\%. "Do not know" responses were considered as partial awareness given the insight to lack of knowledge and granted a score of $50 \%$. Average scores were calculated for the consent components assessed through the questionnaire. Overall scores were categorized into Adequate understanding (71-100\%), Partial understanding (41-70\%) and Inadequate understanding (0-40\%). These cutoffs scores were chosen arbitrary as there was no previous consensus to the definition of adequacy of understanding.

Statistical Package for the Social Sciences (SPSS) was used for all analysis. Nonparametric tests were used to assess for statistically significant differences among the two groups. Results are reported in actual numbers of patients and their percentages in addition to overall response mean scores.

\section{Results}




\section{Patient Characteristics}

PAC-VC enrolled 18 AMI RCTs participants divided into two arms according to the initial informed consent used: 12 participants in the verbal assent arm and 6 participants in the written consent arm. Males were $83.3 \%$ of the total participants. Median age was 54 years of age. English was the first language for $72.2 \%$ of participants and fifty percent had college education. Previous history of MI was observed in only one patient. Previous enrollment into research was reported by 4 (24\%) patients. Previous ambulance transport and hospital admissions were reported by $52.9 \%$ and $70.6 \%$ of participants respectively. Attention, stress, pain and anxiety rated by the participants on a scale from 1-10 during the consent process is shown in Table 1.

\section{Patients' Degree of Understanding and Comprehension}

Responses showed that patients had adequate understanding of most core components of the verbal assent and was comparable to the understanding of written consents as shown in figure 2 .

Participants from both arms had adequate comprehension to the purpose of consent with scores $91.7 \%$ vs $100 \%$ in the verbal and written consent groups respectively, however they had a partial understanding to the details when asked about the purpose of the study with average scores $41.67 \%$ and $66.7 \%$ in verbal and written consents respectively. This was consistent with the overall perspective of patients in both groups as demonstrated by the responses in the second questionnaire. (Tables 2 and 4 )

The concept of randomization was challenging to participants in both groups where they showed inadequate to partial comprehension with an average score of $37.5 \%$ and $50 \%$ in the verbal and written consents respectively. The difference in scores did not reach statistical significance. Participants' comprehension to the risks was adequate in the verbal group while inadequate in the written group $70.8 \%$ vs $33.3 \%$. On the other hand, both groups showed adequate comprehension to the benefits with average scores $70 \%$ and $100 \%$ in the verbal and written consent arms respectively.

Study participants showed adequate comprehension to the concept of autonomy and treatment alternatives in both arms with an average score of $83.3 \%$ vs $91.7 \%$ and $75 \%$ vs $83.3 \%$ in the verbal and written groups respectively.

Participants in both groups equally showed an adequate comprehension to confidentiality with an average score of $83.3 \%$ in both groups.

\section{Patients Perspectives and Attitudes}

Only $33.3 \%$ of patients read the written information. Most patients, $75 \%$ of the verbal arm and $100 \%$ of the written arm did not think written information was very important in making the final decision to choose to participate or not. However, participants from the verbal assent $(75 \%)$ still wanted to have 
written information to be part of the consent process and only $25 \%$ of verbal and $16.7 \%$ of written arms wanted the written information to be presented during the initial consent process. Majority of patients in the written consent group (83.3\%) and 50\% of the verbal assent group felt pressured during the consent process. Also, $75 \%$ of patients in the verbal assent arm, and $100 \%$ of the written consent arm felt that the consent process was not satisfactory. (Table 3)

\section{Post-Verbal/Post-Written Consent Interviews}

REMCON-STEMI patients in the verbal arm were asked to take part of the questionnaire for a second time once completed the formal written consent. Among 12 patients, only 2 agreed to answer the questionnaire for the $2^{\text {nd }}$ time. Overall responses showed knowledge improvement in some areas as displayed in Figure 3. Interestingly, patients' attitudes and opinions did not change after exposure to the written consent.

\section{Discussion}

The role of AMI clinical trials in developing and refining treatment guidelines is essential. However, the emergency nature of AMI as a disease poses extra challenges to obtain an ideal informed consent.

To our knowledge, PAC-VC is the first study to utilize a questionnaire that objectively compares patients' perspectives and comprehension of verbal assent to written consent. Our results show that patients understanding of verbal assent is comparable to written consents with an adequate understanding of most core components of the consent information. These include the purpose of consent, idea of autonomy, benefits, alternative treatments, choice to refuse participation and confidentiality. However, when attention to details was required, participants showed partial to inadequate understanding. Examples include the concept of randomization, blinding, alternative treatments and side effects. These results confirm previous findings demonstrating that patients who consent to clinical trials remember general information about studies, however often have sub-optimal understanding of the specific study details. $(4,7,9-13)$ This was clearly illustrated in our cohort when participants performed poorly in understanding alternative treatments, randomization and side effects. Abstract thinking and complex processing is required to interpret these components and may not be possible and difficult to handle by severely ill patients in an acute phase of a disease. Additionally, it has also been previously suggested that poor understanding and recall to side effects may be influenced by patients inability to accept potentially unpleasant realities.(14) Interestingly, patients in the verbal arm of our cohort showed an adequate understanding of treatment side effects which may argue that verbal information is easier to understand and emphasize the importance of this tool of information delivery.

Most patients in our cohort did not read the provided written information and reported that they did not believe it was very important in making their final decision in regards to participation. Patients did support the importance of having written information available, yet not necessarily to be presented during the acute phase of the consent process. These findings are consistent with the literature as was found 
that patients did not read the written material provided to them prior to making decisions. $(4,8,11-13,15)$ Instead, patients preferred a summary of verbal information and turned to oral explanations as a substitute. Interestingly, $75 \%$ of patients in the verbal assent arm, and $100 \%$ of the written consent arm felt that the consent process was not satisfactory. Such impressions require further exploration.

Delay in treatment of AMI increases the rate of adverse outcomes and risk of death.(16-19) Hence, the consent process required for participation in AMI trials might unduly pressure potential participants and influence patients willingness to consent. The majority of patients (83.3\%) in the written consent arm felt pressured during the consent process. It has been previously shown that participants felt pressured at the time of consent process and rushed into making a prompt decision, which put participants under stress. $(11,15)$ These findings were less observed in the verbal assent arm (50\% of participants). This can be interpreted as reading needs more time and special attention to analyze the facts enlisted in a written format, on the other hand, patients may find oral information and explanations as an easier substitute to process the data and make a quicker decision without feeling pressured.

\section{Strengths And Limitations}

This study to our knowledge is the first to assess patients understanding of verbal assents in comparison to written consents in AMI research. PAC-VC used a multiple-choice questionnaire to objectively assess patients understanding in contrast to previous studies using self-reporting. Unfortunately, there are no standardized testing to quantify comprehension or define how much understanding is satisfactory. Since there are no grading systems, we opted to construct our own to simplify the interpretations of the results. This is certainly a point that can be debated, and may set a stage for further discussions to clarify the definitions of adequate and poor understanding. These are still subjective and one can argue that optimal understanding would require additional set of measures and standards. Study participants were recruited from different AMI trials addressing multiple research questions with diverse complexity and study protocols. Although the COMPLETE trial recruited patients with AMI, patients were in a stable condition in contrary to the acute patients recruited to REMCON and TOTAL. Finally, the study is small, nonrandomized with heterogenous population characteristics (gender, age, education levels) that would plead to cautiously interpret the results to propose a question and an idea rather than claim conclusions.

\section{Conclusion}

PAC-VC is a small, non-randomized prospective study assessing patients' comprehension to verbal assent and written consent in AMI research. Patients had adequate understanding to most components of verbal assent and comparable to those of written consent. Although patients still prefer written information to be part of the consent process, most do not read the written information nor feel that it should necessarily be presented during the acute phase of the consent process. The study results suggest that verbal assent may have a future role as acceptable alternative to the traditional written consent in similar AMI research. These results invite more research in this area with larger studies. 


\section{Abbreviations}

PAC-VC: Patients Acceptance and Comprehension to Written and Verbal Consent; AMI: Acute myocardial infarction; RCT: Randomized clinical trials; ICH: The International Council of Harmonization; REMCONSTEMI: Remote ischemic conditioning in ST-Elevation myocardial infarction research;

COMPLETE: Complete vs Culprit-only Revascularization to Treat Multi-vessel Disease After Early PCI for STEMl; TOTAL: routine aspiration ThrOmbecTomy with PCl versus PCI ALone in patients with STEMI undergoing primary PCl;EMS: Emergency Medical services (EMS).

\section{Declarations}

Ethics approval and consent to participate:

The study received research ethics approval from the University of Alberta Research Ethics Board at the University of Alberta, study title PAC-VC, ID number Pro00046145.

All participants provided written consent prior to participation.

Consent for publication:

Not applicable.

Availability of data and material:

The datasets used and/or analysed during the current study available from the corresponding author on reasonable request.

Competing interests:

The authors declare that they have no competing interests.

Funding:

No funding was obtained for this study.

Contributions:

RW contributed to the conception and design of the study. RK contributed to data collection and data analysis. All authors were involved in data interpretation. The first draft of the manuscript was written by RK and RW and all authors commented on subsequent versions of the manuscript. All authors have read and approved the manuscript.

Acknowledgements: 
Not applicable.

\section{References}

1. Ilfeld BM. Informed consent for medical research: an ethical imperative. Reg Anesth Pain Med. 2006;31(4):353-7.

2. Faden RR, Beauchamp TL. A history and theory of informed consent: Oxford University Press; 1986.

3. Smith HL. Myocardial infarction-Case studies of ethics in the consent situation. Soc Sci Med. 1974;8(7):399-404.

4. Williams BF, French JK, White HD. Informed consent during the clinical emergency of acute myocardial infarction (HERO-2 consent substudy): A prospective observational study. Lancet. 2003;361(9361):918-22.

5. Ockene IS, Miner J, Shannon TA, Gore JM, Weiner BH, Ball SP. The consent process in the Thrombolysis in Myocardial Infarction (TIMI--phase I) trial. Clin Res. 1991;39(1):13-7.

6. Gammelgaard A, Rossel P, Mortensen OS. Patients' perceptions of informed consent in acute myocardial infarction research: A Danish study. Social Science and Medicine. 2004;58(11):2313-24

7. Yuval R, Halon DA, Flugelman MY, Lewis BS. Perceived patient comprehension in acute and chronic cardiovascular clinical trials. Cardiology. 2003;99(2):68-71.

8. Dickert NW, Fehr AE, Llanos A, Scicluna VM, Samady H. Patients' views of consent for research enrollment during acute myocardial infarction. Acute Card Care. 2015;17(1):1-4.

9. Kucia AM, Horowitz JD. Is informed consent to clinical trials an "upside selective" process in acute coronary syndromes? American Heart Journal. 2000;140(1):94-7.

10. Yuval R, Halon DA, Merdler A, Khader N, Karkabi B, Uziel K, et al. Patient comprehension and reaction to participating in a double-blind randomized clinical trial (ISIS-4) in acute myocardial infarction. Archives of Internal Medicine. 2000;160(8):1142-6.

11. Ågård A, Hermerén G, Herlitz J. Patients' experiences of intervention trials on the treatment of myocardial infarction: Is it time to adjust the informed consent procedure to the patient's capacity? Heart. 2001;86(6):632-7.

12. Gammelgaard A. Informed consent in acute myocardial infarction research. Journal of Medicine and Philosophy. 2004;29(4):417-34.

13. Gammelgaard A, Mortensen OS, Rossel P. Patients' perceptions of informed consent in acute myocardial infarction research: A questionnaire based survey of the consent process in the DANAMI2 trial. Heart. 2004;90(10):1124-8.

14. Riecken HW, Ravich R. Informed consent to biomedical research in Veterans Administration Hospitals. JAMA. 1982;248(3):344-8.

15. Gammelgaard A, Rossel P, Mortensen OSOS, Investigators D-. Patients' perceptions of informed consent in acute myocardial infarction research: a Danish study. Soc Sci Med. 2004;58(11):2313-24. 
16. Indications for fibrinolytic therapy in suspected acute myocardial infarction: collaborative overview of early mortality and major morbidity results from all randomised trials of more than 1000 patients. Fibrinolytic Therapy Trialists' (FTT) Collaborative Group. Lancet. 1994;343(8893):311-22.

17. Newby LK, Rutsch WR, Califf RM, Simoons ML, Aylward PE, Armstrong PW, et al. Time from symptom onset to treatment and outcomes after thrombolytic therapy. GUSTO-1 Investigators. J Am Coll Cardiol. 1996;27(7):1646-55.

18. Zijlstra F, Patel A, Jones M, Grines CL, Ellis S, Garcia E, et al. Clinical characteristics and outcome of patients with early $(<2 \mathrm{~h})$, intermediate $(2-4 \mathrm{~h})$ and late $(>4 \mathrm{~h})$ presentation treated by primary coronary angioplasty or thrombolytic therapy for acute myocardial infarction. Eur Heart $\mathrm{J}$. 2002;23(7):550-7.

19. De Luca G, Suryapranata H, Ottervanger JP, Antman EM. Time delay to treatment and mortality in primary angioplasty for acute myocardial infarction: every minute of delay counts. Circulation. 2004;109(10):1223-5.

\section{Tables}

Table 1 Baseline Characteristics (Consent Type)

\begin{tabular}{|llll|}
\hline & Verbal & Written & Total \\
\hline $\mathrm{N}(\%)$ & $12(66.7)$ & $6(33.3)$ & 18 \\
\hline Males & $11(91.7)$ & $4(66.7)$ & $15(83.3)$ \\
\hline Age & 60.83 (Median 57.5) & 48.83 (Median 51.5) & $56.83(\mathrm{M}=54)$ \\
\hline $1^{\text {st }}$ language is English & $7(58.3)$ & $6(100)$ & $13(72.2)$ \\
\hline College education & $6(50)$ & $3(50)$ & $9(50)$ \\
\hline PREVIOUS HISTORY & & & $1(6)$ \\
\hline MI & $1(9)$ & 0 & $4(24)$ \\
\hline Research & $3(27.3)$ & $1(16.7)$ & $12(70.6)$ \\
\hline Hosp. Admission & $9(81.8)$ & $3(50)$ & $9(52.9)$ \\
\hline Ambulance transport & $6(54.5)$ & $3(50)$ & 5.88 \\
\hline PHYSCAL SYMPTOMS (Mean out of 10) & & 7 \\
\hline Attention & 5.73 & 6.17 & 5.18 \\
\hline Stress & 7.18 & 6.67 & 6.88 \\
\hline Pain & 5.27 & 5 & 6.83 \\
\hline Anxiety & 6.91 & & \\
\hline
\end{tabular}


Table 2 Objective Questionnaire Scores Described in Means Out of 100

\begin{tabular}{|lll|}
\hline Consent component & Consent type & \\
\cline { 2 - 3 } & Verbal Assent & Written Consent \\
\hline Purpose of consent & 91.67 & 100.00 \\
\hline Purpose of study & 41.67 & 66.67 \\
\hline Duration of study & 45.83 & 25.00 \\
\hline Nature of study intervention & 50.00 & 66.67 \\
\hline Number of study groups & 50.00 & 75.00 \\
\hline Understanding of alternative treatments & 33.33 & 33.33 \\
\hline Randomization & 37.50 & 50.00 \\
\hline Blindness & 25.00 & 25.00 \\
\hline Side effects & 70.83 & 33.33 \\
\hline Contacts in case of side effects & 62.50 & 25.00 \\
\hline Compensation in case of harm & 58.33 & 75.00 \\
\hline Voluntariness of withdraw & 83.33 & 91.67 \\
\hline Treatment options if refused to participate & 75.00 & 83.33 \\
\hline Benefits of participation & 70.00 & 100.00 \\
\hline Financial benefits of participation & 83.33 & 91.67 \\
\hline Confidentiality & 83.33 & 83.33 \\
\hline Whom to contact for any complaints & 83.33 & 75.00 \\
\hline Total Score & 61.47 & 64.71 \\
\hline
\end{tabular}

Table 3 Patients Perspectives 


\begin{tabular}{|c|c|c|c|}
\hline & & \multicolumn{2}{|c|}{ Consent type } \\
\hline & & $\begin{array}{l}\text { Verbal } \\
\text { Assent }\end{array}$ & $\begin{array}{l}\text { Written } \\
\text { consent }\end{array}$ \\
\hline & & $\mathrm{N} \%$ & $\mathrm{~N} \%$ \\
\hline \multirow{3}{*}{$\begin{array}{l}\text { I would prefer only verbal information presented during the } \\
\text { consent process }\end{array}$} & Agree & $2(16.7 \%)$ & $2(33.3 \%)$ \\
\hline & $\begin{array}{l}\text { Cannot } \\
\text { decide }\end{array}$ & $1(8.3 \%)$ & $2(33.3 \%)$ \\
\hline & Disagree & $9(75.0 \%)$ & $2(33.3 \%)$ \\
\hline \multirow{3}{*}{$\begin{array}{l}\text { I would prefer written information presented during the } \\
\text { consent process }\end{array}$} & Agree & $3(25.0 \%)$ & $1(16.7 \%)$ \\
\hline & $\begin{array}{l}\text { Cannot } \\
\text { decide }\end{array}$ & $3(25.0 \%)$ & $3(50.0 \%)$ \\
\hline & Disagree & $6(50.0 \%)$ & $2(33.3 \%)$ \\
\hline \multirow{3}{*}{$\begin{array}{l}\text { I read the written information about the research study before } \\
\text { making my decision }\end{array}$} & Agree & $2(16.7 \%)$ & $2(33.3 \%)$ \\
\hline & $\begin{array}{l}\text { Cannot } \\
\text { decide }\end{array}$ & $2(16.7 \%)$ & $0(0.0 \%)$ \\
\hline & Disagree & $8(66.7 \%)$ & $4(66.7 \%)$ \\
\hline \multirow{3}{*}{$\begin{array}{l}\text { I believe written information is very important in making my } \\
\text { final decision to participate }\end{array}$} & Agree & $2(16.7 \%)$ & $0(0.0 \%)$ \\
\hline & $\begin{array}{l}\text { Cannot } \\
\text { decide }\end{array}$ & $1(8.3 \%)$ & $0(0.0 \%)$ \\
\hline & Disagree & $9(75.0 \%)$ & $6(100.0 \%)$ \\
\hline \multirow[t]{3}{*}{ I feel satisfied and comfortable with the consent process } & Agree & $0(0.0 \%)$ & $0(0.0 \%)$ \\
\hline & $\begin{array}{l}\text { Cannot } \\
\text { decide }\end{array}$ & $3(25.0 \%)$ & $0(0.0 \%)$ \\
\hline & Disagree & $9(75.0 \%)$ & $6(100.0 \%)$ \\
\hline \multirow{3}{*}{$\begin{array}{l}\text { I felt pressured by time when I made my decision during the } \\
\text { consent process }\end{array}$} & Agree & $6(50.0 \%)$ & $5(83.3 \%)$ \\
\hline & $\begin{array}{l}\text { Cannot } \\
\text { decide }\end{array}$ & $3(25.0 \%)$ & $1(16.7 \%)$ \\
\hline & Disagree & $3(25.0 \%)$ & $0(0.0 \%)$ \\
\hline
\end{tabular}

Table 4 Patients Subjective Understanding 


\begin{tabular}{|c|c|c|c|c|c|}
\hline \multirow{3}{*}{ Items examined } & & \multicolumn{4}{|c|}{ Consent type } \\
\hline & & \multicolumn{2}{|c|}{ Verbal Assent } & \multicolumn{2}{|c|}{ Written Consent } \\
\hline & & Count & $\begin{array}{l}\text { Column } \\
\mathrm{N} \%\end{array}$ & Count & $\begin{array}{l}\text { Column } \\
\mathrm{N} \%\end{array}$ \\
\hline \multirow[t]{3}{*}{ You understand the purpose of study } & Agree & 1 & $8.3 \%$ & 0 & $0.0 \%$ \\
\hline & $\begin{array}{l}\text { Cannot } \\
\text { decide }\end{array}$ & 2 & $16.7 \%$ & 0 & $0.0 \%$ \\
\hline & Disagree & 9 & $75.0 \%$ & 6 & $100.0 \%$ \\
\hline \multirow{3}{*}{$\begin{array}{l}\text { You know how long you will be enrolled in this } \\
\text { study. }\end{array}$} & Agree & 3 & $25.0 \%$ & 3 & $50.0 \%$ \\
\hline & $\begin{array}{l}\text { Cannot } \\
\text { decide }\end{array}$ & 4 & $33.3 \%$ & 0 & $0.0 \%$ \\
\hline & Disagree & 5 & $41.7 \%$ & 3 & $50.0 \%$ \\
\hline \multirow{3}{*}{$\begin{array}{l}\text { You understand what will be done in this study } \\
\text { and what you are being asked to do }\end{array}$} & Agree & 1 & $8.3 \%$ & 1 & $20.0 \%$ \\
\hline & $\begin{array}{l}\text { Cannot } \\
\text { decide }\end{array}$ & 3 & $25.0 \%$ & 0 & $0.0 \%$ \\
\hline & Disagree & 8 & $66.7 \%$ & 4 & $80.0 \%$ \\
\hline \multirow{3}{*}{$\begin{array}{l}\text { You recognize the experimental part that may be } \\
\text { used in your treatment. (Study intervention) }\end{array}$} & Agree & 1 & $8.3 \%$ & 0 & $0.0 \%$ \\
\hline & $\begin{array}{l}\text { Cannot } \\
\text { decide }\end{array}$ & 2 & $16.7 \%$ & 0 & $0.0 \%$ \\
\hline & Disagree & 9 & $75.0 \%$ & 6 & $100.0 \%$ \\
\hline \multirow{3}{*}{$\begin{array}{l}\text { You recognize the possible risks or discomforts } \\
\text { that may result due to participation in this study }\end{array}$} & Agree & 0 & $0.0 \%$ & 0 & $0.0 \%$ \\
\hline & $\begin{array}{l}\text { Cannot } \\
\text { decide }\end{array}$ & 2 & $16.7 \%$ & 1 & $16.7 \%$ \\
\hline & Disagree & 10 & $83.3 \%$ & 5 & $83.3 \%$ \\
\hline \multirow{3}{*}{$\begin{array}{l}\text { You recognize the possible benefits you may } \\
\text { gain from participation }\end{array}$} & Agree & 0 & $0.0 \%$ & 0 & $0.0 \%$ \\
\hline & $\begin{array}{l}\text { Cannot } \\
\text { decide }\end{array}$ & 2 & $16.7 \%$ & 0 & $0.0 \%$ \\
\hline & Disagree & 10 & $83.3 \%$ & 6 & $100.0 \%$ \\
\hline \multirow{3}{*}{$\begin{array}{l}\text { You recognize the possible benefits that may } \\
\text { help future patients. }\end{array}$} & Agree & 0 & $0.0 \%$ & 0 & $0.0 \%$ \\
\hline & $\begin{array}{l}\text { Cannot } \\
\text { decide }\end{array}$ & 0 & $0.0 \%$ & 0 & $0.0 \%$ \\
\hline & Disagree & 12 & $100.0 \%$ & 6 & $100.0 \%$ \\
\hline $\begin{array}{l}\text { You know alternative options/treatments you } \\
\text { may have if you had chosen to NOT participate. }\end{array}$ & Agree & 2 & $16.7 \%$ & 1 & $16.7 \%$ \\
\hline
\end{tabular}




\begin{tabular}{|lllllc|} 
& \multicolumn{1}{c}{$\begin{array}{l}\text { Cannot } \\
\text { decide }\end{array}$} & 1 & $8.3 \%$ & 1 & $16.7 \%$ \\
\cline { 2 - 6 } & Disagree & 9 & $75.0 \%$ & 4 & $66.7 \%$ \\
\hline $\begin{array}{l}\text { You understand that your information is being } \\
\text { kept confidential and disclosed only to } \\
\text { authorized personnel }\end{array}$ & Agree & 0 & $0.0 \%$ & 0 & $0.0 \%$ \\
\cline { 2 - 6 } & $\begin{array}{l}\text { Cannot } \\
\text { decide }\end{array}$ & 0 & $0.0 \%$ & 0 & $0.0 \%$ \\
\hline & Disagree & 12 & $100.0 \%$ & 6 & $100.0 \%$ \\
\hline
\end{tabular}

\begin{tabular}{|c|c|c|c|c|c|}
\hline \multirow{3}{*}{$\begin{array}{l}\text { You know whom you should contact in case of side } \\
\text { effects or injuries that may result due to participation in } \\
\text { the study }\end{array}$} & Agree & 1 & $8.3 \%$ & 2 & $33.3 \%$ \\
\hline & $\begin{array}{l}\text { Cannot } \\
\text { decide }\end{array}$ & 2 & $16.7 \%$ & 0 & $0.0 \%$ \\
\hline & Disagree & 9 & $75.0 \%$ & 4 & $66.7 \%$ \\
\hline \multirow{3}{*}{$\begin{array}{l}\text { You know what compensation or treatment is available } \\
\text { for you in case of side effects or injury }\end{array}$} & Agree & 3 & $25.0 \%$ & 3 & $50.0 \%$ \\
\hline & $\begin{array}{l}\text { Cannot } \\
\text { decide }\end{array}$ & 3 & $25.0 \%$ & 0 & $0.0 \%$ \\
\hline & Disagree & 6 & $50.0 \%$ & 3 & $50.0 \%$ \\
\hline \multirow{3}{*}{$\begin{array}{l}\text { You understand that your participation is completely } \\
\text { voluntary and it is not going to affect your treatment if } \\
\text { you choose to withdraw }\end{array}$} & Agree & 0 & $0.0 \%$ & 0 & $0.0 \%$ \\
\hline & $\begin{array}{l}\text { Cannot } \\
\text { decide }\end{array}$ & 0 & $0.0 \%$ & 0 & $0.0 \%$ \\
\hline & Disagree & 12 & $100.0 \%$ & 6 & $100.0 \%$ \\
\hline \multirow{3}{*}{$\begin{array}{l}\text { You understand that you can withdraw from this study at } \\
\text { any time you wish to do so }\end{array}$} & Agree & 0 & $0.0 \%$ & 0 & $0.0 \%$ \\
\hline & $\begin{array}{l}\text { Cannot } \\
\text { decide }\end{array}$ & 0 & $0.0 \%$ & 0 & $0.0 \%$ \\
\hline & Disagree & 12 & $100.0 \%$ & 6 & $100.0 \%$ \\
\hline \multirow{3}{*}{$\begin{array}{l}\text { You know whom you should contact in case you have } \\
\text { questions, comments, concerns or complaints about the } \\
\text { study }\end{array}$} & Agree & 2 & $16.7 \%$ & 2 & $33.3 \%$ \\
\hline & $\begin{array}{l}\text { Cannot } \\
\text { decide }\end{array}$ & 2 & $16.7 \%$ & 0 & $0.0 \%$ \\
\hline & Disagree & 8 & $66.7 \%$ & 4 & $66.7 \%$ \\
\hline
\end{tabular}

\section{Figures}




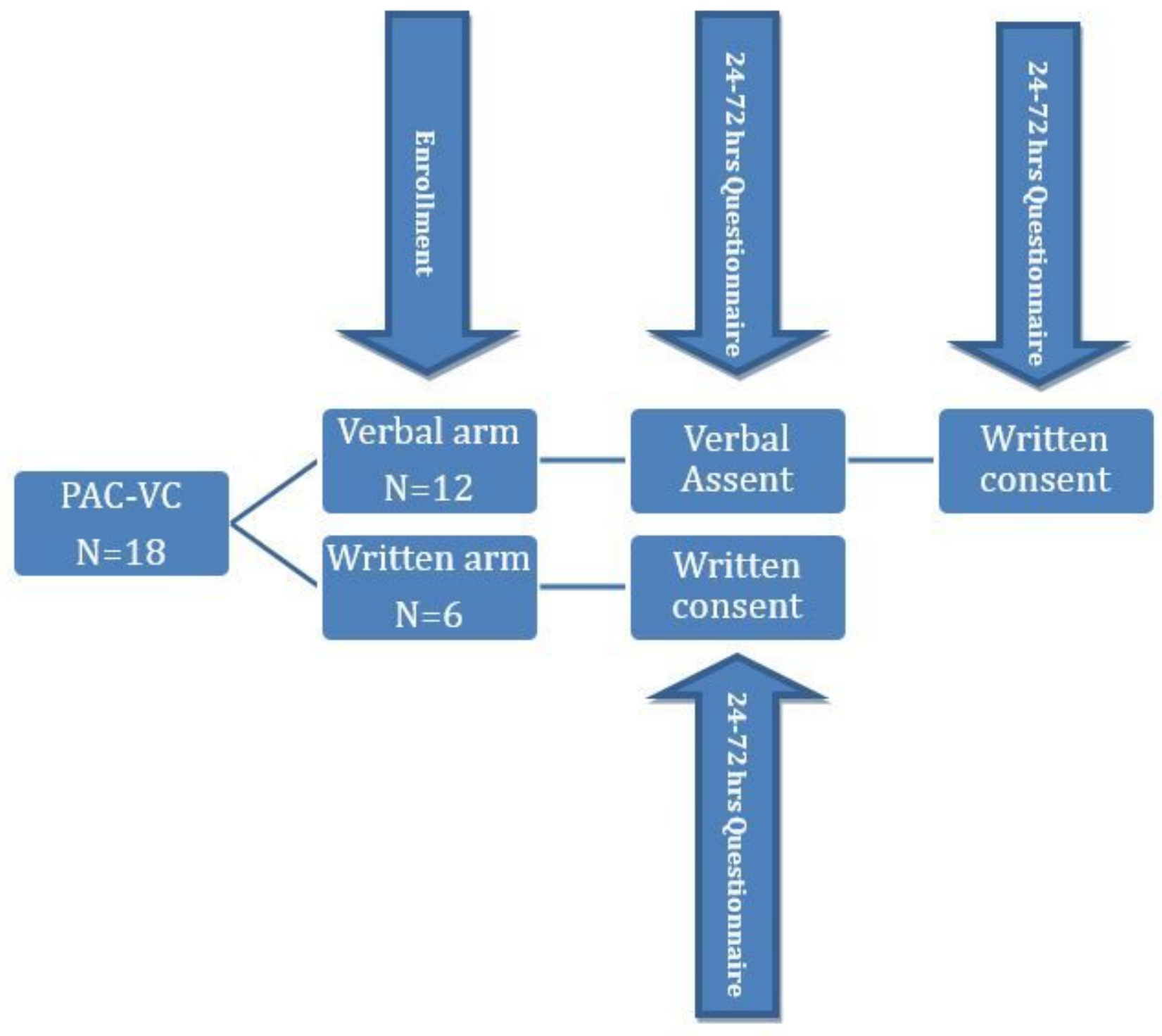

Figure 1

PAC-VC Methods Flow Chart 


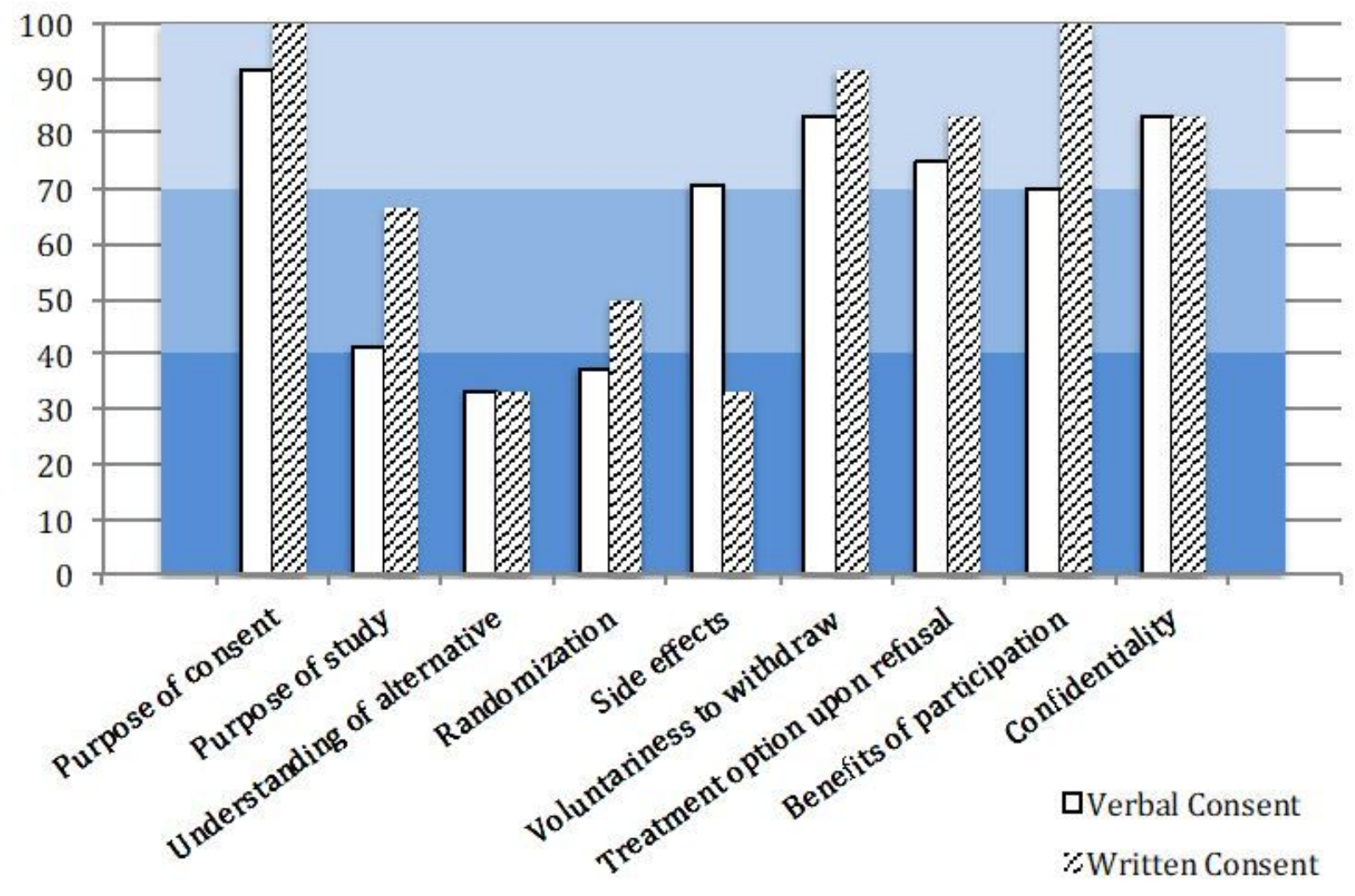

Figure 2

Total Score of Patients' Understanding to the Components of Consent 


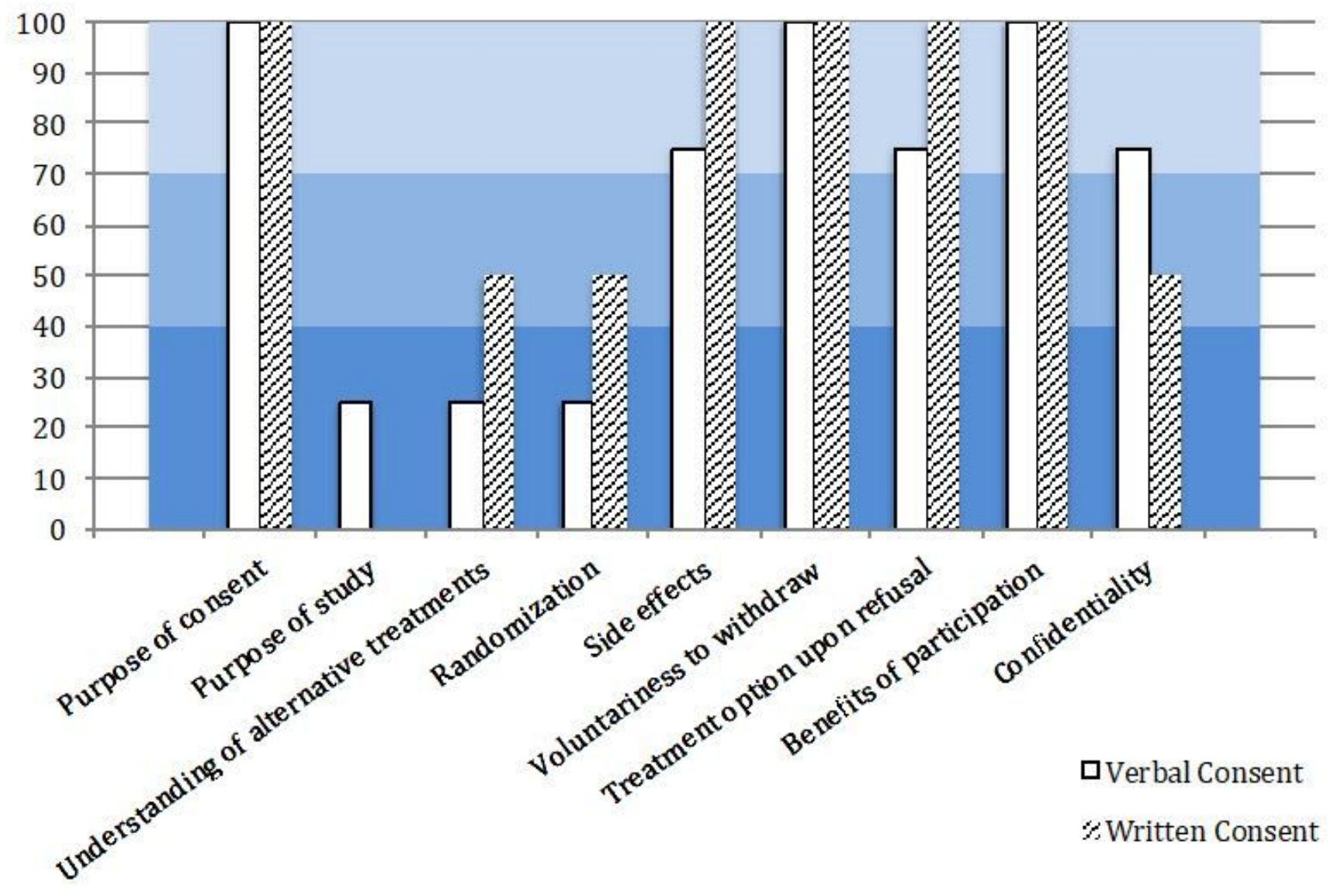

Figure 3

Post-Verbal/Post-Written Consent Interviews Responses 